ORIGINAL RESEARCH

\title{
Adaptation to High Altitude in Sherpas: Association with the Insertion/Deletion Polymorphism in the Angiotensin-Converting Enzyme Gene
}

\author{
Yunden Droma, MD, PhD; Masayuki Hanaoka, MD, PhD; Buddha Basnyat, MD; Amit Arjyal, MD; Pritam \\ Neupane, MD; Anil Pandit, MD; Dependra Sharma, MD; Michiko Ito, MD; Naoyuki Miwa, MD; Yoshihiko \\ Katsuyama, PhD; Masao Ota, PhD; Keishi Kubo, MD, PhD \\ From the First Department of Medicine, Shinshu University School of Medicine, Matsumoto, Japan (Drs Droma, Hanaoka, Ito, Miwa, and \\ Kubo); Nepal International Clinic, Katmandu, Nepal (Dr Basnyat); Mountain Medicine Society of Nepal, Kathmandu, Nepal (Drs Basnyat, \\ Arjyal, Neupane, Pandit, and Sharma); Department of Pharmacy, Shinshu University Hospital, Matsumoto, Japan (Dr Katsuyama); and \\ Department of Legal Medicine, Shinshu University School of Medicine, Matsumoto, Japan (Dr Ota).
}

\begin{abstract}
Objective.- Sherpas are well-known for their physical strength at high altitudes. They adapt to high altitude so well that little acute or chronic mountain sickness has been documented in them. The possible genetic basis for this adaptation is, however, unclear. The objective of this study was to elucidate the genetic background underlying this characteristic among Sherpas with respect to the angiotension-converting enzyme (ACE) gene.

Methods.-We enrolled 105 Sherpa volunteers in Namche Bazaar (3440 meters) and 111 nonSherpa Nepalese volunteers in Kathmandu Valley (1330 meters) in Nepal. Information about highaltitude exposure and physiological phenotypes was obtained via fieldwork investigation. The genotype of the insertion/deletion (I/D) polymorphism in the $A C E$ gene was identified by polymerase chain reaction. Serum ACE activity was also measured.

Results.-The distribution of the $I$ dominant genotype $(I I \& I D)$ and the $I$ allelic frequency were significantly more prevalent in Sherpas (II \& ID: 94.3\%, I allele: 73.3\%) than in non-Sherpas (II \& $I D: 85.6 \%, P=.035 ; I$ allele: $64.0 \%, P=.036$ ). Moreover, despite residing at high altitude, the circulating ACE levels of Sherpas were statistically similar to those of non-Sherpas at low altitudes (Sherpas: $14.5 \pm 0.4 \mathrm{IU} / \mathrm{L} / 37^{\circ} \mathrm{C}$; non-Sherpas: $14.7 \pm 0.4 \mathrm{IU} / \mathrm{L} / 37^{\circ} \mathrm{C} ; P=.755$ ).

Conclusions. - These findings suggest that the overrepresented $I$ allele of the ACE gene in Sherpas might be one of the fundamental genetic factors responsible for maintaining physiological low-altitude ACE activity at high altitude, which may have an advantageous physiological role in adapting to a high-altitude environment.
\end{abstract}

Key words: angiotensin-converting enzyme (ACE), gene, high altitude, polymorphism, Sherpas

\section{Introduction}

Among the nearly 140 million people residing at altitudes over 2500 meters above sea level worldwide, ${ }^{1}$ Sherpas are a minority ethnic population that has permanently resided for almost 500 years along the Himalayan region in Nepal. "Sherpa" means "coming from the east," which refers to the Eastern Tibetan region of Kham from which Sherpa origin can be traced. About

Corresponding author: Masayuki Hanaoka, MD, PhD, First Department of Medicine, Shinshu University School of Medicine, 3-1-1 Asahi, Matsumoto 390-8621, Japan (e-mail: masayuki@hsp.md.shinshuu.ac.jp).
500 years ago, ancestors of the present Sherpa population arrived in Nepal and settled in the northern side of the Solu-Khumbu district of Nepal. Elevation of human settlements in this area ranges from 1600 meters to 4000 meters. Due to the location and their well-known physical strength at high altitudes, Sherpas play key roles in expeditions to Mount Everest and other famous peaks. Since the beginning of the last century when Sherpas were first employed by British expedition teams to Mount Everest, ${ }^{2,3}$ their extraordinary mountaineering prowess and hardiness have brought them recognition in mountaineering circles. A variety of studies have inves- 
tigated their morphology and physiology, ${ }^{4-8}$ demonstrating that they adapt to and perform at high altitude so well that they are rarely affected by acute or chronic mountain sickness. Genetic adaptation likely plays a role in shaping the morphological and physiological differences as detected in previous investigations. The current study was designed to examine the underlying genetics that might explain variations in the complex traits associated with this adaptation.

Recently, a significant amount of work has been undertaken to investigate the insertion $(I) /$ deletion $(D)$ polymorphism of the angiotensin-converting enzyme ( $A C E$ ) gene ( $A C E$ I/D polymorphism) in relation to human adaptation to high altitude. ${ }^{9-11}$ The $A C E$ gene is chosen primarily as a candidate gene because the $I$ allele has been shown to be associated with Caucasian mountain climbers who ascended to extremely high altitudes without supplemental oxygen. ${ }^{12}$ The objective of this study was to investigate $A C E I / D$ polymorphism in Sherpas in order to evaluate the possible involvement of this polymorphism in their high-altitude adaptation.

\section{Materials and methods}

\section{SETTINGS AND PARTICIPANTS}

The current study was approved by the Ethics Committee of Shinshu University (Matsumoto, Japan) and the Nepal Health Research Council (Kathmandu, Nepal). The protocol was developed in accordance with the principles outlined in the Declaration of Helsinki of the World Medical Association. ${ }^{13}$ Informed consent was obtained from all participants prior to the study.

The fieldwork was carried out in Namche Bazaar village, located at 3440 meters, where almost all of the approximately 1500 inhabitants are Sherpas. Namche Bazaar is one of the most popular trekking junctions in proximity to Mount Everest and other famous peaks. It is about 200 kilometers from Kathmandu, the capital of Nepal, and the only way to access the village is through a mountain trekking path. The Sherpas are a small ethnic minority with a population of 5000 in the Solu-Khumbu district, 30000 in Nepal, and less than 50000 total worldwide. $^{14}$

The Solu-Khumbu district is in close geographic proximity (200 kilometers) to the Kathmandu Valley in Nepal. Since the time of Sherpa settlement in the SoluKhumbu area, they have never been genetically isolated, as there has been almost constant immigration of Tibetans into the area, and, conversely, they have contributed to the overall present population of Nepal by emigration. ${ }^{2,3}$ It has been established that in the Jirel tribe (East Nepal), $30 \%$ of genes are of Sherpa origin. ${ }^{15}$ Indeed, the diversity in the human genome may introduce the "ascertainment bias" in the comparison between the Sherpas and the non-Sherpas in Kathmandu in terms of genetic polymorphisms. ${ }^{16}$ However, Prugnolle et al ${ }^{17}$ analyzed 377 autosomal microsatellite loci comprising 51 populations distributed worldwide and demonstrated that geography predicts neutral genetic diversity of human populations. In addition, specific for the ACE I/D polymorphism, it is distributed continuously in populations in the Asia continent, including Chinese, Japanese, Bangladeshi, Indian, and Sikh, ${ }^{18}$ and reportedly Nepalese as well. ${ }^{19}$ Thus, the non-Sherpa Nepalese in Kathmandu were chosen as a reference control in comparison with Sherpas in the current comparative genetic study. Except for difference in high-altitude exposure between the 2 groups, other environmental factors such as nutrition, physical training, and medical health services were felt to be essentially equivalent in the current Sherpa and the non-Sherpa Nepalese groups.

\section{FIELDWORK PROTOCOL}

Only Sherpas with Sherpa clan ties were recruited. Clan ties were determined on the basis of self-report and confirmed by a senior native Sherpa who was a coordinator for our fieldwork. All enrolled Sherpas were born and permanently resided in Namche Bazaar and were unrelated to each other in the first and second degree. Information regarding demographics, health status, altitude of residence, occupation, and mountaineering history was obtained during an interview. Symptoms of chronic mountain sickness (CMS), ${ }^{20}$ such as headache, dizziness, dyspnea, sleep disturbances, physical and mental fatigue, and cyanosis were specifically evaluated during the interviews. A percutaneous arterial oxygen saturation $\left(\mathrm{SpO}_{2}\right)$ and heart rate were measured using a pulse oximeter (Pulsox-3, Minolta, Osaka, Japan) with a probe connected to a finger. Venous blood samples were taken and placed in tubes containing ethylenediaminetetraacetic acid (EDTA) anticoagulant for DNA extraction and into tubes containing beads and clot activator for serum preparation.

The fieldwork for the non-Sherpa Nepalese control group was conducted in Kathmandu Valley (1330 meters), Nepal. The same protocol was followed as for the Sherpas in Namche Bazaar.

\section{LABORATORY EXPERIMENTS}

Blood samples were frozen and transported from Namche Bazaar to Japan for analysis. All laboratory experiments were undertaken in Shinshu University, Japan. 
Table 1. Phenotypic data for the study groups $\dagger$

\begin{tabular}{lccc}
\hline \multicolumn{1}{c}{ Phenotypes } & Sherpas & non-Sherpas $\$$ & P Value* \\
\hline Altitude (meters) & 3440 & 1330 & \\
No. of subjects & 105 & 111 & $.388^{* *}$ \\
Male:female & $44: 61$ & $29.9 \pm 0.8$ & .251 \\
Age (years) & $31.2 \pm 0.8$ & $20.7 \pm 1.0$ & $<.0001$ \\
Time in residence at home altitude (years) & $30.8 \pm 0.8$ & none & $.0001^{* *}$ \\
No. of trekking guides and porters (\%) & $33(31.4)$ & $2688.6 \pm 150.4$ & $<.0001$ \\
Altitude ascended in average (meters) & $5701.4 \pm 119.1$ & 5300 & $<.0001$ \\
Highest altitude reached (meters) & 8850 & $96.6 \pm 0.2$ & .0013 \\
Oxygen saturation $(\%)$ & $93.3 \pm 0.2$ & $86.8 \pm 1.5$ & .755 \\
Heart rate (bpm) & $80.7 \pm 1.1$ & $14.7 \pm 0.4$ & \\
ACE activity (IU/L/37 $\left.{ }^{\circ} \mathrm{C}\right)$ & $14.5 \pm 0.4$ & & \\
\hline
\end{tabular}

$\dagger$ Plus-minus values are mean \pm SEM. ACE indicates angiotensin converting enzyme; bpm $=$ beats per minute.

$\$$ Non-Sherpas indicates non-Sherpa Nepalese residing in Kathmandu Valley, Nepal.

*Compared by unpaired $t$ test, except $* *$ compared by contingency table $(2 \times 2)$, df $=1$.

The ACE activity in serum was measured using a colorimetric method. ${ }^{21}$

Genomic DNA was extracted from venous blood leukocytes by phenol extraction of sodium dodecyl sulfatelysed and proteinase K-treated cells. The ACE I/D polymorphism of a 287-base pair (bp) sequence in intron 16 of the human $A C E$ gene (GenBank accession no. $\mathrm{X} 62855)$ was amplified by polymerase chain reaction (PCR) in a thermal cycler (GeneAmp PCR System 9700, $P E$ Applied Biosystems, Norwalk, CT, USA) using primers described by Rigat et al. ${ }^{22}$ The fragments of a 287-bp sequence were determined by $2 \%$ agarose gel electrophoresis with ethidium bromide staining to visualize the 490-bp $I$ allele and the 190 -bp $D$ allele. ${ }^{22}$ The $D D$ genotype was reconfirmed by insertion allele-specific amplification according to Lindpaintner's proto$\mathrm{col}^{23}$

\section{STATISTICAL ANALYSIS}

Continuous data are expressed as mean \pm standard error of the mean (SEM). The differences in the continuous variables between the 2 groups were analyzed by unpaired Student's $t$ test while the categorical data were analyzed by contingency table $(2 \times 2)$. The genotypes were counted and the allele frequencies were derived from the genotypes. A chi-square test was used to confirm that the observed genotype distributions were in Hardy-Weinberg equilibrium (HWE). The differences of genotypic distributions and allelic frequencies between the 2 groups were examined by chi-square test. Additionally, since the inheritance manner of the $I$ allele has not been clarified in these 2 populations, the effects of the $I$ allele assuming additive ( $I I$ versus $I D$ versus $D D$ ), dominant (II and $I D$ versus $D D$ ), and recessive (II versus $I D$ and $D D$ ) modes of inheritance were calculated. The odds ratio and its approximate $95 \%$ confidence interval (CI) were calculated. The association of ACE I/D polymorphism with circulating ACE activity was analyzed by one-way analysis of variance. Statistical significance was considered to be at $P<.05$.

\section{Results}

\section{STUDY POPULATIONS}

After health screening, a total of 105 unrelated Sherpas (female $=61$, male $=44$ ) met our criteria for subject selection and were sampled in Namche Bazaar (Table 1). They had dwelt at Namche Bazaar for $30.8 \pm 0.8$ years, almost equal to their average age of $31.2 \pm 0.8$ years, confirming that they were permanent residents in Namche Bazaar. A matched group (according to sample size, gender, and age) of 111 unrelated non-Sherpa Nepalese was sampled in Kathmandu, Nepal (Table 1). They had dwelt at Kathmandu for $20.7 \pm 1.0$ years, which was significantly shorter than their average age of 29.9 \pm 0.8 years $(P<.0001)$. This group consisted mostly of university students, housewives, and business men/ women, some of whom were immigrants to Kathmandu. None of them, however, migrated from places higher than Kathmandu or had relations of Sherpa ethnicity. None of the subjects including the Sherpas and the nonSherpas had ever participated in any professional physical training programs. None of the Sherpas complained of any symptoms of CMS. Thirty-three out of the 105 (31.4\%) Sherpas were trekking guides and porters but none of the 111 non-Sherpas did this job $(P<.0001)$. 
Table 2. Genotypic distributions and allelic frequencies of the $A C E I / D$ polymorphism in Sherpas and non-Sherpas $\dagger$

\begin{tabular}{lcc}
\hline & Sherpas & Non-Sherpas \\
\hline Genotypic Distribution & & \\
$I I(\%)$ & $55(52.4)$ & $47(42.3)$ \\
$I D(\%)$ & $44(41.9)$ & $48(43.2)$ \\
$D D(\%)$ & $6(5.7)$ & $16(14.5)$ \\
Significance* & $\chi^{2}=5.18, P=.075$ \\
Allelic Frequency & & \\
$I(\%)$ & $154(73.3)$ & $142(64.0)$ \\
$D(\%)$ & $56(26.7)$ & $80(36.0)$ \\
Significance** & $\chi^{2}=4.39, P=.036$ \\
Odds ratio & 1.55 & \\
$95 \%$ CI & $1.03-2.33$ & \\
\end{tabular}

$\dagger$ Non-Sherpas indicates non-Sherpa Nepalese residing in Kathmandu Valley, Nepal. CI indicates confidence interval; $D=$ deletion allele; $I=$ insertion allele.

*Comparison of the genotypic distribution by $\chi^{2}$ test $(3 \times 2$ contingency table, $\mathrm{df}=2$ ).

**Comparison of the allelic frequency by $\chi^{2}$ test $(2 \times 2$ contingency table, df =1).

As expected, the Sherpas reached significantly higher altitudes than the non-Sherpas in their mountaineering histories $(P<.0001)$. Among the Sherpas, 13 men had participated in expeditions to mountains over 8000 meters and 6 of them had reached the summit of Mount Everest. Although the $\mathrm{SpO}_{2}$ was significantly lower in the Sherpas at 3440 meters altitude $(93.3 \% \pm 0.2 \%)$ than the non-Sherpas at 1330 meters altitude $(96.6 \% \pm$ $0.2 \%, P<.0001)$, the heart rate of Sherpas was significantly slower $(80.7 \pm 1.1$ beats $/ \mathrm{min}[\mathrm{bpm}])$ than that of the non-Sherpas $(86.8 \pm 1.5 \mathrm{bpm}, P=.0013)$. The circulating ACE level of the Sherpas at high altitude was statistically similar to that of the non-Sherpas at low altitude $\left(14.5 \pm 0.4 \mathrm{IU} / \mathrm{L} / 37^{\circ} \mathrm{C}\right.$ in Sherpas vs $14.7 \pm 0.4$ $\mathrm{IU} / \mathrm{L} / 37^{\circ} \mathrm{C}$ in non-Sherpas, $\left.P=.755\right)$.

\section{GENOTYPIC DISTRIBUTIONS AND ALLELIC FREQUENCIES OF THE ACE I/D POLYMORPHISM IN THE STUDY GROUPS}

The genotypic distributions and the allelic frequencies of the ACE I/D polymorphism in each group are summarized in Table 2 . The observed genotypic distributions were in agreement with the distributions predicted by HWE in both groups (Sherpas: $P=.76$; non-Sherpas: $P=.80)$. There was no significant difference in the genotypic distribution between the 2 groups $(P=.075)$. However, the $I$ allele was significantly more prevalent among the Sherpas (73.3\%) than the non-Sherpas
Table 3. Effects of the $I$ allele in the modes of additive, dominant, and recessive inheritances in Sherpas $\dagger$

\begin{tabular}{lcl}
\hline Modes of Analysis & Odds Ratio $(95 \%$ CI) & P Value \\
\hline$I I$ vs. $I D$ vs. $D D \ddagger$ & $1.89(0.90-6.60)$ & $.075^{*}$ \\
$I I+I D$ vs. $D D \S$ & $2.78(1.07-7.19)$ & $.035^{* *}$ \\
$I I$ vs. $I D+D D \|$ & $1.50(0.88-2.56)$ & $.140^{* *}$ \\
\hline
\end{tabular}

$\dagger \mathrm{CI}$ indicates confidence interval; $D=$ deletion allele; $I=$ insertion allele.

\$Additive effect of the $I$ allele.

$\S$ Dominant effect of the $I$ allele.

$\|$ Recessive effect of the $I$ allele.

*Calculated by $\chi^{2}$ test $(3 \times 2$ contingency table, $\mathrm{df}=2)$.

$* *$ Calculated by $\chi^{2}$ test $(2 \times 2$ contingency table, $\mathrm{df}=1)$.

(64.0\%, $P=.036)$ with an odds ratio of $1.55(95 \% \mathrm{CI}$ $=1.03-2.33)$. Furthermore, the $I$ dominant genotypes (II and $I D$ ) were significantly more frequent in the Sherpas than the non-Sherpas $(P=.035$; odds ratio $=2.78 ; 95 \%$ $\mathrm{CI}=1.07-7.19$, Table 3 ), suggesting a dominant effect of the $I$ allele in the Sherpas.

\section{SERUM ACE ACTIVITY AND ACE I/D POLYMORPHISM}

Serum ACE activity of the Sherpas at high altitude was similar to that of the non-Sherpas at low altitude (Table 1). In Sherpas, the serum ACE activity according to the $A C E$ I/D genotypes was as follows: II, $12.6 \pm 0.5 \mathrm{IU} /$ $\mathrm{L} / 37^{\circ} \mathrm{C} ; I D, 16.1 \pm 0.6 \mathrm{IU} / \mathrm{L} / 37^{\circ} \mathrm{C} ; D D, 20.8 \pm 2.0 \mathrm{IU} /$ $\mathrm{L} / 37^{\circ} \mathrm{C}$ (Figure). Correspondingly, in the non-Sherpas the serum ACE activity according to the ACE I/D genotypes were: $I I, 12.2 \pm 0.4 \mathrm{IU} / \mathrm{L} / 37^{\circ} \mathrm{C} ; I D, 16.2 \pm 0.5$ $\mathrm{IU} / \mathrm{L} / 37^{\circ} \mathrm{C} ; D D, 17.8 \pm 1.1 \mathrm{IU} / \mathrm{L} / 37^{\circ} \mathrm{C}$ (Figure). There were no significant differences in the serum ACE activity for the $I I, I D$, and $D D$ genotypes between the 2 groups. In both groups, the serum ACE activity was correlated with the genotypes, being highest in the subjects with $D D$ genotype, intermediate in $I D$ heterozygotes, and lowest in $I I$ homozygotes $(P<.001)$.

\section{Discussion}

Consistent with published literature about the history, lifestyle, ${ }^{2,3}$ and physiology of Sherpas, ${ }^{4-8}$ this study's findings related to their mountaineering histories, absence of symptoms of CMS, and the relation of low $\mathrm{SpO}_{2}$ with normal heart rate re-enforced that the Sherpa group is a distinctive population permanently residing at over 3000 meters altitude and is significantly different from the study population originating from lower altitudes. The statistical similarity of circulating ACE activ- 


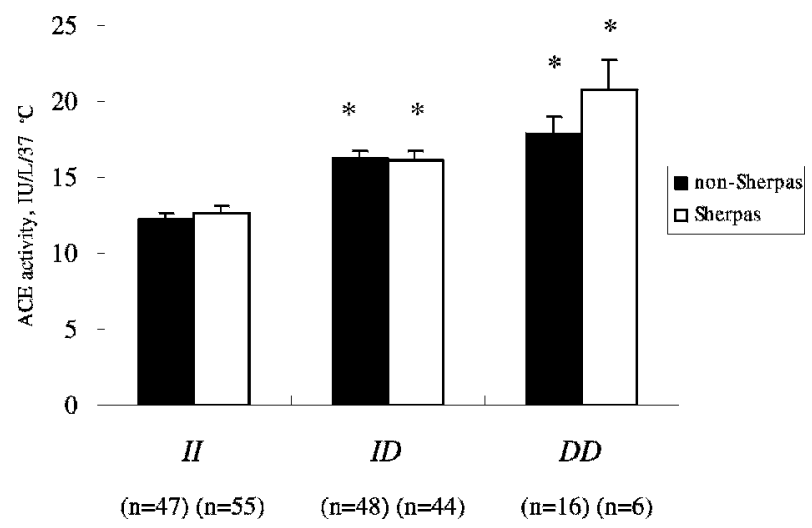

Figure. Graph of serum ACE activity according to the $A C E$ $I / D$ polymorphism in Sherpas and non-Sherpas. $\dagger$ The ACE activity in both populations is correlated with the genotypes, being significantly highest in the subjects with $D D$ genotype, intermediate in $I D$ heterozygotes, and lowest in II homozygotes. ${ }^{*} P<.001$ compared with the $I I$ homozygotes. The number of subjects is shown in parentheses. †Non-Sherpas indicates non-Sherpa Nepalese residing in Kathmandu Valley, Nepal.

ity between the 2 groups may be further evidence of this difference when considering that ACE levels may be influenced by mountaineering and exposure to altitude. ${ }^{24-26}$ We found that the $I$ allelic frequency and $I$ dominant genotypic distribution (II and ID) of ACE I/D polymorphism were significantly overrepresented in the Sherpas compared to the non-Sherpas at low altitudes, providing insight into the genetic background of these 2 groups. The prevalence of the $I$ allele was commonly associated with low ACE activity in both groups irrespective of either ethnicity or altitude of residence. We propose that the overrepresented $I$ allele of the ACE I/D polymorphism may play one of the fundamental genetic roles in maintaining low-altitude circulating ACE activity at high altitude and may benefit the Sherpas by increasing tolerance to hypoxia at high altitude.

As a key enzyme in the circulating renin-angiotensin system (RAS), ACE degrades vasodilator kinins and generates vasoconstrictor angiotensin II (Ang II) that has many other actions, including stimulation of aldosterone release predominantly via the Ang II type 1 receptor. ${ }^{27}$ ACE plays an important role in the physiology and pathophysiology of humans at high altitudes ${ }^{28}$ probably through its effects on skeletal muscle, ${ }^{29}$ cardiac function, ${ }^{30}$ sodium and fluid retention via the RAS, ${ }^{31}$ and possibly on the respiratory center via the nucleus tractus solitarii as shown in a rat model. ${ }^{32} A C E$ mRNA was highly expressed in pulmonary vessels of rats with highaltitude hypoxic pulmonary hypertension, ${ }^{33}$ a sign indicating a failure in high-altitude adaptation. When hu- mans are exposed to high altitudes, the circulating ACE levels tend to increase with ascent and decrease with descent back to sea level. ${ }^{26}$ Furthermore, an augmented ACE response is involved in the development of highaltitude pulmonary edema, ${ }^{34}$ a high-altitude maladaptation disorder occurring in healthy, unacclimatized, lowaltitude natives who are rapidly exposed to a high-altitude environment. ACE converts Ang I to Ang II and increases circulating aldosterone levels. Both act to induce vasoconstriction and fluid- $\mathrm{Na}^{+}$retention, which play important roles in the generation of high-altitude disorders. ${ }^{28}$ On the other hand, ACE activity was within $\pm 10 \%$ of normal sea-level values in high-altitude-adapted mountaineers after 2 to 4 weeks at 6300 meters. ${ }^{35}$ All of this suggests that maintaining physiologic low-altitude ACE activity at high altitudes, as found in our study, may contribute to adaptive physiology by contributing to an adaptive respiratory response to hypoxia, $, 8,36$ maintaining normal pulmonary artery pressures, ${ }^{34}$ and contributing to sodium and fluid balance. ${ }^{28}$

The level of circulating ACE is, however, significantly influenced by environmental stimuli, such as hypoxia, ${ }^{24}$ mountaineering, and altitude. ${ }^{25-27}$ ACE activity in individuals may vary by more than $100 \%$ over 6 months, ${ }^{37}$ suggesting that environmental factors indeed cause marked fluctuations. How could Sherpas maintain physiological low-altitude levels of circulating ACE activity at high altitudes? We hypothesize that the prevalence of the $I$ allele of the ACE I/D polymorphism is one of the fundamental contributing factors for a relatively low ACE activity in Sherpas at high altitudes. Cloning of the human $A C E$ gene has led to the discovery of a polymorphism, consisting of either the absence $(D)$ or the presence $(I)$ of a 287-bp DNA fragment inside intron 16. ${ }^{22}$ ACE I/D polymorphism accounts for $47 \%$ of the total phenotypic variance of serum ACE in healthy Caucasians, demonstrating that $A C E I / D$ polymorphism is a major genetic factor in determining serum ACE concentration. ${ }^{38}$ Whatever the race, individuals with II genotype have the lowest circulating ACE levels, $D D$ homozygotes have the highest ACE levels, and ID heterozygotes have intermediate levels. ${ }^{9,10,38}$ One outstanding study demonstrated an allele skew with a significant excess of the $I$ allele and $I I$ genotype in elite male British mountaineers who ascended beyond 7000 meters without the use of supplemental oxygen. ${ }^{12}$ Following a line of this study, it was shown that the $I$ allele of the $A C E$ gene is associated with maintenance of $\mathrm{SpO}_{2}$ during rapid ascent to altitudes over 5000 meters. ${ }^{39}$ Regarding high-altitude residents, Qadar Pasha et $\mathrm{al}^{10}$ reported that the $I$ allele and $I I$ genotype of ACE I/D polymorphism were significantly prevalent in high-altitude natives of Ladakhis, who reside for their lifetime at over 3600 me- 
ters compared to low-land residents in the same region. All of these investigations provide evidence to support our hypothesis.

Rupert et al, ${ }^{11}$ however, did not find a significant difference in the distribution of $A C E I / D$ polymorphism between high-altitude and low-altitude Native American populations in the Andes. Nevertheless, as the authors explained, one of the reasons for their negative results may be that the 600 generations during which people have lived at high altitudes in the Andes is too short a period for new genetic variants to be established by natural selection. The Sherpa ethnic group in the Himalayan region migrated from the Tibetan Plateau. ${ }^{2,3}$ It has been shown that human beings have been living in Tibet for possibly 50000 years. $^{1}$ According to an evolution hypothesis, the greater duration of the Tibetan population at high altitudes would be expected to result in an advantageous adaptation, as judged by the existence of attributes associated with improved chance of reproductive success. ${ }^{1,40}$ Another discrepancy is that Aldashev et al ${ }^{9}$ reported that the $I$ allele and $I I$ genotype of $A C E$ $I / D$ polymorphism were infrequent in Kyrgyz highlanders permanently living at an altitude over 3000 meters in the Tien-Shan and Pamir mountains compared to Kyrgyz lowlanders residing in Bishkek at 600 meters above sea level. The "low-land control" group in that study, however, was not entirely representative of the native Bishkek population as the subjects were recruited from patients at hospitals, albeit for conditions unrelated to the study. ${ }^{9}$ The authors were suspicious of the reliability of their results and explained that the circulating ACE activity in the Kyrgyz population may be under greater control from other polymorphisms in the $A C E$ gene or other regulatory genes because only $16.3 \%$ of the variance in ACE activity was contributed by the ACE I/D polymorphism in the Kyrgyz population, compared to $47 \%$ in White populations. ${ }^{38}$

The major limitation of our study is the difference of ancestry of the 2 study populations. Theoretically, it would be advantageous to compare genotypes between Sherpas fully adapted to high altitudes with those having lost such adaptation. It is, however, difficult to obtain large enough sample sizes of Sherpas who have lost adaptation to high altitudes because of the fact that most Sherpas live at high altitudes throughout their lifetime. Thus, we chose a population in Kathmandu who reside geographically near to Namche Bazaar as a reference group principally based on the study by Prugnolle et al ${ }^{17}$ in which the authors demonstrated that geography predicts neutral genetic diversity of human populations and on a investigation ${ }^{18}$ in that study the authors demonstrated that the $A C E I / D$ polymorphism was distributed continuously in populations in the Asia continent, including
Chinese, Japanese, Bangladeshi, Indian, and Sikh, and reportedly Nepalese as well. ${ }^{19}$ Therefore, we believe that the comparison of the $A C E I / D$ polymorphism between the 2 populations in the current study is valid and reliable.

Nevertheless, the significance of the distribution of $A C E$ I/D polymorphism between the Sherpas and nonSherpas was marginal $(P=.03)$. Several other polymorphisms in the $A C E$ gene have been reported to be associated with serum ACE level.41,42 The discrepancy between the different $A C E$ allele frequencies and the similar ACE levels in the 2 populations could be due to different genetic haplotypic relationships between the Sherpas and non-Sherpas. The ACE I/D polymorphism only partly accounts for the genetic adaptation of Sherpas living at high altitudes. It is said that genetic factors account for about $50 \%$ of the variance of the physiological phenotypes regarding the hypoxic response system in high-altitude populations worldwide. ${ }^{43}$ Our current association analysis using the $A C E$ candidate gene is a primary genetic approach to understanding human adaptation to high altitudes in Sherpas. Further research is needed to evaluate the full genotypic and phenotypic aspects of populations adapted to high-altitude existence.

\section{Acknowledgments}

This study was supported by a grant-in-aid from the Japan Society for the Promotion of Science (JSPS), No. 16004240. Dr Droma was the recipient of a JSPS postdoctoral fellowship (P04240). Partial funding for the field investigation was provided by the Alumni Association of First Departments of Medicine, Shinshu University. The authors would like to thank the Nepal Health Research Council (Katmandu, Nepal) for their cooperation. The authors would especially like to thank all the Sherpa and non-Sherpa Nepalese volunteers for participating in the study. Additional thanks to Dr. Toshio Kobayashi for his support throughout the study.

We declare that there is no conflict of interest with the present study.

\section{References}

1. Niermeyer S, Zamudio S, Moore LG. The people. In: Hornbein TF, Schoene RB, eds. High Altitude: An Exploration of Human Adaptation. New York, NY: Marcel Dekker Inc; 2001:43-100.

2. Fisher JF, ed. Sherpas: Reflections on Change in Himalayan Nepal. Delhi, India: Oxford India Paperbacks; 1997.

3. Ortner S, ed. Sherpas Through their Ritual. Cambridge, London: Cambridge University Press; 1986.

4. Garrido E, Segura R, Capdevila A, Pujol J, Javierre C, 
Ventura JL. Are Himalayan Sherpas better protected against brain damage associated with extreme altitude climbs? Clin Sci (Lond). 1996;90:81-85.

5. Hochachka PW, Clark CM, Holden JE. Stanley C, Ugurbil $\mathrm{K}$, Menon RS. ${ }^{31} \mathrm{P}$ magnetic resonance spectroscopy of the Sherpa heart: a phosphocreatine/adenosine triphosphate signature of metabolic defense against hypobaric hypoxia. Proc Natl Acad Sci USA. 1996;93:1215-1220.

6. Holden JE, Stone CK, Clark CM, et al. Enhanced cardiac metabolism of plasma glucose in high-altitude natives: adaptation against chronic hypoxia. J Appl Physiol. 1995;79: 222-228.

7. Morpurgo G, Arese P, Bosia A, et al. Sherpas living permanently at high altitude: a new pattern of adaptation. Proc Natl Acad Sci U S A. 1976;73:747-751.

8. Santolaya RB, Lahiri S, Alfaro RT, Schoene RB. Respiratory adaptation in the highest inhabitants and highest Sherpa mountaineers. Respir Physiol. 1989;77:253-262.

9. Aldashev AA, Sarybaev AS, Sydykov AS, et al. Characterization of high-altitude pulmonary hypertension in the Kyrgyz: association with angiotensin-converting enzyme genotype. Am J Respir Crit Care Med. 2002;166:13961402.

10. Qadar Pasha MA, Khan AP, Kumar R, et al. Angiotensin converting enzyme insertion allele in relation to high altitude adaptation. Ann Hum Genet. 2001;65:531-536.

11. Rupert JL, Kidd KK, Norman LE, Monsalve MV, Hochachka PW, Devine DV. Genetic polymorphisms in the rennin-angiotensin system in high-altitude and low-altitude native American populations. Ann Hum Genet. 2003; 67:17-25.

12. Montgomery HE, Marshall R, Hemingway H, et al. Human gene for physical performance. Nature. 1998;393: 221-222.

13. World Medical Association Declaration of Helsinki. Recommendations guiding physicians in biomedical research involving human subjects. JAMA. 1997;277:925-926.

14. Ethnologue 14th. Sherpa: a language of Nepal. Available at: http://www.ethnologue.com/14/show_language.asp? code $=$ SCR/. Accessed September 11, 2006.

15. Blangero J. Population structure analysis using polygenic traits: estimation of migration matrices. Hum Biol. 1990; 62:27-48.

16. Clark AG, Hubisz MJ, Bustamante CD, Williamson SH, Nielsen R. Ascertainment bias in studies of human genome-wide polymorphism. Genome Res. 2005;15:14961502.

17. Prugnolle F, Manica A, Balloux F. Geography predicts neutral genetic diversity of human populations. Curr Biol. 2005;15:R159-R160.

18. Zamam MM, Yoshiike N, Tanaka H. Dissecting the contradictory findings of angiotensin converting enzyme genetic polymorphism with blood pressure and hypertension. Bangladesh Med Res Counc Bull. 2001;27:90-95.

19. Umemura S, Kawasaki T, Ishigami T, et al. Angiotensin- converting enzyme gene polymorphism in Nepal. J Hum Hypertens. 1998;12:527-531.

20. Monge CC, Leon-Valarde F, Arregui A. Chronic mountain sickness in Andeans. In: Hornbein TF, Schoene RB, eds. High Altitude: An Exploration of Human Adaptation. New York: Marcel Dekker Inc; 2001:815-838.

21. Kasahara Y, Ashihara Y. Colorimetry of angiotensin-I converting enzyme activity in serum. Clin Chem. 1981;27: 1922-1925.

22. Rigat B, Hubert C, Corvol P, Soubrier F. PCR detection of the insertion/deletion polymorphism of the human angiotensin converting enzyme gene (DCP1) (dipeptidyl carboxypeptidase 1). Nucleic Acids Res. 1992;20:1433.

23. Lindpaintner K, Pfeffer MA, Kreutz R, et al. A prospective evaluation of an angiotensin-converting enzyme gene polymorphism and the risk of ischemic heart disease. $N$ Engl J Med. 1995;332:706-711.

24. Milledge JS, Catley DM. Renin, aldosterone, and converting enzyme during exercise and acute hypoxia in humans. J Appl Physiol. 1982;52:320-323.

25. Milledge JS, Catley DM, Ward MP, Williams ES, Clarke CR. Renin-aldosterone and angiotensin-converting enzyme during prolonged altitude exposure. J Appl Physiol. 1983;55:699-702.

26. Kamikomaki N, Nishioka O. Serum angiotensin-converting enzyme (ACE) is altered at altitude. High Alt Med Biol. 2004;5:465-466.

27. Erdos E, Skidgel RA. The angiotensin I-converting enzyme. Lab Invest. 1987;56:345-348.

28. Woods DR, Montgomery HE. Angiotensin-converting enzyme and genetics at high altitude. High Alt Med Biol. 2001;2:201-210.

29. Henriksen EJ, Jacob S. Modulation of metabolic control by angiotensin converting enzyme (ACE) inhibition. $J$ Cell Physiol. 2003;196:171-179.

30. de Rosa ML, Cardace P, Rossi M, Baiano A, de Cristofaro A. Comparative effects of chronic ACE inhibition and AT1 receptor blocked losartan on cardiac hypertrophy and renal function in hypertensive patients. J Hum Hypertens. 2002;16:133-140.

31. Guthrie GP. Angiotensin receptors: physiology and pharmacology. Clin Cardiol. 1995;18:29-34.

32. Paton JF, Kasparov S. Differential effects of angiotensin II on cardiorespiratory reflexes mediated by nucleus tractus solitarii - a microinjection study in the rat. J Physiol. 1999;521:213-225.

33. Morrell NW, Atochina EN, Morris KG, Danilov SM, Stenmark KR. Angiotensin converting enzyme expression is increased in small pulmonary arteries of rats with hypoxiainduced pulmonary hypertension. J Clin Invest. 1995;96: 1823-1833.

34. Kumar R, Pasha Q, Khan AP, Gupta V. Renin angiotensin aldosterone system and $A C E I / D$ gene polymorphism in high-altitude pulmonary edema. Aviat Space Environ Med. 2004;75:981-983.

35. Milledge JS, Catley DM, Blume FD, West JB. Renin, an- 
giotensin-converting enzyme, and aldosterone in humans on Mount Everest. J Appl Physiol. 1983;55:1109-1112.

36. Patel S, Woods DR, Macleod NJ, et al. Angiotensin-converting enzyme genotype and the ventilatory response to exertional hypoxia. Eur Respir J. 2003;22:755-760.

37. Ribichini F, Steffenino G, Dellavalle A, et al. Plasma activity and insertion/deletion polymorphism of angiotensin I-converting enzyme: a major risk factor and a marker of risk for coronary stent restenosis. Circulation. 1998;97: 147-154.

38. Rigat B, Hubert C, Alhenc-Gelas F, Cambien F, Corvol P, Soubrier F. An insertion/deletion polymorphism in the angiotensin I-converting enzyme gene accounting for half the variance of serum enzyme levels. J Clin Invest. 1990; 86:1343-1346.

39. Woods DR, Pollard AJ, Collier DJ, et al. Insertion/deletion polymorphism of the angiotensin I-converting enzyme gene and arterial oxygen saturation at high altitude. Am J Respir Crit Care Med. 2002;166:362-366.

40. Niermeyer S, Yang P, Shanmina, Drolkar, Zhuang J, Moore LG. Arterial oxygen saturation in Tibetan and Han infants born in Lhasa, Tibet. N Engl J Med. 1995;333: $1248-1252$.

41. Kramers C, Danilov SM, Deinum J, et al. Point mutation in the stalk of angiotensin-converting enzyme causes a dramatic increase in serum angiotensin-converting enzyme but no cardiovascular disease. Circulation. 2001;104: 1236-1240.

42. Zhu X, McKenzie CA, Forrester T, et al. Localization of a small genomic region associated with elevated ACE. Am J Hum Genet. 2000;67:1144-1153.

43. Hochachka PW. Mechanism and evolution of hypoxia-tolerance in humans. $J$ Exp Biol. 1998;201:1243-1254. 